\title{
Investigating Rain Attenuation Models for Satellite Links in Tropical Nigeria
}

\author{
Abayomi Isiaka O. Yussuff**1, Ibukun E. Koleoso ${ }^{2}$, Nor Hisham Haji Khamis ${ }^{3}$ \\ ${ }^{1,2}$ Lagos State University, Lagos, Nigeria \\ ${ }^{3}$ Universiti Teknologi Malaysia, Skudai, Malaysia
}

\section{Article Info \\ Article history: \\ Revised Jan 9, 2018 \\ Accepted Jan 31, 2018 \\ Keyword: \\ Prediction model \\ Attenuation \\ Slant path \\ Rain rate \\ Tropical region}

Received Dec 14, 2017

\begin{abstract}
The analyses of rain models for satellite communication links of $\mathrm{Ku}$ and $\mathrm{Ka}$ bands in Lagos, Nigeria is the focus of this paper. The choice of these frequency bands was informed by the acknowledged fact that satellite signal fading and outages are predominant at those bands. The ITU-R P. 618-12 is the globally adopted prediction model; temperate, equatorial and tropical regions, inclusive. However, there was need to review the suitability of this model especially as it concerned equatorial and tropical stations. Rainfall data spanning a period of three years were collected from Nigerian Meteorological Agency (NIMET). The ITU-R P. 618-12 model along with some renowned prediction models were analyzed and their performances with the locally recorded measurement data were compared to establish their suitability or otherwise. The results obtained suggested ITU-R P. 618-12 exhibited the overall best performance at $12 \mathrm{GHz}$ while DAH showed best performance at $26 \mathrm{GHz}$, even as both models underestimated and overestimated the measurement at $\mathrm{Ku}$ and $\mathrm{Ka}$ bands respectively. Again, at both frequencies, SST presented the worst performances.
\end{abstract}

Copyright $\odot 2018$ Institute of Advanced Engineering and Science. All rights reserved.

\section{Corresponding Author:}

Abayomi Isiaka O. Yussuff,

Lagos State University, Lagos, Nigeria.

Email: abayomi.yussuff@lasu.edu.ng

\section{INTRODUCTION}

Microwave signals can be transmitted by satellite telecommunication systems at various frequency bands; and these include $\mathrm{C}$ band (4-8 GHz), Ku band (12-18 GHz), Ka band (26.5-40 GHz), and V band (40$75 \mathrm{GHz}$ ) [1]. Improvement in telecommunication and broadcasting globally, occasioned congestion in frequency bands below $10 \mathrm{GHz}$; compelling microwave designers to migrate to higher frequencies [2]. However, deployments of millimeter wave band for communication links provides certain benefits such as larger available bandwidths [3], with consequent high-speed service delivery and higher download and upload speeds at lower costs. At frequencies beyond $10 \mathrm{GHz}$, rain events cause severe attenuation to propagating signals; thus necessitating the need for fade margin assessment of signals during rain events [3]. Rain has been conformed to be a major contributor to signal loss at millimeter wavebands. At these frequency bands, absorption, depolarization, and scattering by hydrometers such as rain, clouds, hail, ice crystals, or wet snow can result in degradation in the transmitted signal power; resulting in signal attenuation [4]. With modern communications, slant path communication had since become a foremost technology owing to its unique characteristics like wide footprints, unlimited geographical coverage, overall reduction in cost of deployment, notwithstanding the distance [5]. For slant path systems operating at millimeter wavebands, the propagation signal is incontrovertibly prone to signal outage due to rainfall, and this is even more pronounced tropical region, as a result of the peculiar nature of the rain precipitatations.

Rainfalls are generally classified into convective and stratiform rain types. This classification is premised on mechanisms which prompt cooling, condensation and associated rain. Precipitation occurs in 
clouds not cooled down to the freezing point, through the process of coalescence. Convective rains, including local storms and strong showers, occur when updrafts of hot and moist air acquire enough power; hence coalesced to produce cumulo-nimbus clouds. The raindrops which form about the same time at the bottom of the cloud are transported by the updrafts up to an altitude where their concentration increases relatively quickly and then fall back to the ground due to violent downdraft. As a result of atmospheric instability due to heat and moisture, thunderstorms are more frequent in equatorial and tropical regions [6]. Convective rainfall is linked to clouds produced beneath the $0^{\circ} \mathrm{C}$ isotherm and are inspired by the robust campaign of air masses instigated by metamorphoses in tropospheric pressure. During this development, water drops are formed; growing in size culminating in rainfalls. The coverage area is several $\mathrm{km}$ and lasts just a couple of minutes. In stratiform rains, the updrafts that maintain clouds are so weak that rain particles which form at the cloud top slowly gather and descend while increasing in size. The concept of stratiform precipitation is often used to describe rains in temperate regions. Stratiform rain emanates from development of small ice particles aggregating to form larger ones, with growing particles becoming unstable in the process of transition the melting layer; morphing into raindrops. Stratiform rain has a widespread of a few hundreds of $\mathrm{km}$ with an average duration surpassing one hour; and with a vertical scale equaling the height of the BrightBand [6].

Satellite communication enables two or more earth stations communicate with each other through a radio relay system. The radio signals while being transmitted through the atmosphere, during rain events, are mitigated by absorption and scattering through the transmission medium (the atmosphere). More so, the troposphere has a lot of water vapour molecules, carbon monoxide molecules, oxygen molecules, and various aerosols such as snow, fog and rain; and all these affects radio signals, leading to continual absorption, reflection and scattering, which causes energy reduction (and attenuation) [5]. Rain attenuation can be described as the product of "specific attenuation" in $\mathrm{dB} / \mathrm{km}$ and the "effective propagation path length" in $\mathrm{km}$. The ratio of the attenuation due to rainfall to the specific attenuation is referred to as the point rain rate while the product of the "path reduction factor" and the "physical path length". The concept of effective path length is a technique to average out the spatial inhomogeneity that is inherent in rain rate, and consequently, the specific attenuation. Due to spatial inhomogeneity in rain rate which largely fluctuates with rainfall intensity, changes in path length reduction factor can be described as a function of rain rate or its corresponding time exceedances. Attenuation can therefore be derived from direct measurements or can be predicted from the knowledge of long-term rain rate. Attenuation, $A_{\% p}$, which is exceeded at $\% p$ of time can be derived from:

$$
\begin{aligned}
& A_{\% p}\left[\gamma\left(R_{\% p}\right), d_{e f f}\left(R_{\% p, d}\right)\right]=\gamma_{\% p} d_{e f f} \\
& \gamma_{\% p}=k R_{\% p}^{\alpha} \\
& d_{e f f}=d r_{\% p}
\end{aligned}
$$

Where $R_{\% p}(\mathrm{~mm} / \mathrm{hr})$ is the rain rate exceeded at $\% p$ of the time, $r_{\% p}$ is the path reduction factor at the same time percentage, $d(\mathrm{~km})$ is the radio path length. Parameters $k$ and $\alpha$ depend on frequency, elevation angle, rain temperature and signal polarization.

\subsection{Overview of Rain Attenuation Prediction Models Used}

Some published rain attenuation prediction models have claimed global applicability. Some of them have been applied in this paper for the purpose of testing for suitability or otherwise at the station of interest. These are:

\subsubsection{Simple attenuation model (SAM)}

One of the most widely used slant path rain attenuation prediction models is the Simple Attenuation Model [7]; which incorporates individual characteristics of the stratiform and convective rain types in its formulation. It employs the point rainfall rate of the location of interest to compute the attenuation time series. The major procedures are;

The attenuation:

$$
A=\gamma L_{S} ; R_{\% p} \leq 10(\mathrm{~mm} / \mathrm{hr})
$$

Where $L_{S}$ is the slant path length of the satellite's line of sight (LOS) from the ground station. Also, 


$$
L_{S}=\frac{H_{R}-H_{S}}{\sin \theta}(k m)
$$

For $R>10 \mathrm{~mm} / \mathrm{hr}$, the effective rain height $\left(H_{R}\right)$ is subject to the rain rate when convective rainfalls are considered. This is so because convective storms forces rain far higher into the atmosphere; extending the slant path [8]. $H_{S}$ is station's height above the mean sea level.

The slant path attenuation is computed employing a modified value of effective path length using the expression:

$$
A=\gamma \frac{1-\exp \left[-\not b \ln \left(\frac{R_{\% p}}{10}\right)\right] L_{S} \cos \theta}{\not b \ln \left(\frac{R_{\% p}}{10}\right) \cos \theta} ; R_{\% p}>10 \mathrm{~mm} / \mathrm{hr}
$$

Where $b$ is an empirical constant of $1 / 22$.

The following empirical expressions for effective rain height $H_{R}$ were derived, based on measurement data:

$$
H_{R}=\left\{\begin{array}{c}
H_{0} ; R \leq 10 \mathrm{~mm} / \mathrm{hr} \\
H_{0}+\log \left(\frac{R}{10}\right) ; R>10 \mathrm{~mm} / \mathrm{hr}
\end{array}\right.
$$

Again, $H_{R}(\mathrm{~km})$ is the rain height, $L_{S}(\mathrm{~km})$ is the slant path up to rain height, $H_{0}(\mathrm{~km})$ is the $0^{0} \mathrm{C}$ isotherm height above mean sea level and its value can be obtained from the isotherm chats of ITUR. P.839-4 [9]..

\subsubsection{Synthetic Storm Technique (SST) Prediction Model}

The synthetic storm technique (SST) was originally introduced by [10], specifically for terrestrial radio link, and was premised on the concept of the Hamilton-Marshall "synthetic storm". The SST input data was the rainfall rate time series over a physical distance by adopting a storm translation velocity in transforming time to distance. The synthesized storms express rainfall rate $(R)$ as a function of distance $(\mathcal{X}$ ) by aggregating the statistical physiognomies of an enormous quantities of synthetic storms [11]. The transformation of rain rate to specific attenuation $(\gamma)$ and by extension, the attenuation, across a distance ( $L$ ) was achieved by Equation (8).

$$
A\left(x_{0}, L\right)=\int_{x_{0}}^{x_{0}+L} \gamma(x) d x(d B)
$$

Other essential inputs in the formulation of SST are advection velocity of rain cells and the slant path length of the location of interest. The SST slant path vertical structure is modeled into tropospheric two layers, A and B. Layer A represents the rain layer where precipitation occurs while layer B is the melting layer, where ice transforms into water as it begins to melt. Layer A comprised homogenous rain precipitation $\left(R_{A}\right)$ and layer B symbolise ice with apparent rain rate $\left(R_{B}\right)$. The combination of both is expressed as:

$$
R_{B}=3.134 R_{A}(\mathrm{~mm} / \mathrm{hr})
$$

The resultant slant path rain attenuation is:

$$
A=\int_{0}^{L_{A}} K_{A} R^{\alpha_{A}}\left(x_{0}+\Delta x_{0}, \zeta\right) \delta \zeta+K_{B}(3.134)^{\alpha_{\mathbf{B}}} \int_{L_{A}}^{L_{B}} R^{\alpha_{B}}\left(x_{0}, \zeta\right) \delta \zeta(d B)
$$

$\zeta$ is the distance measured along the satellite slant path, while $k$ and $\alpha$ are statistical coefficients which correspond to the satellite signal elevation angle, polarization, rain drop size distribution and 
frequency of operation. All these parameters are available in the ITU-R P. 838-3 [12] for water at $20^{\circ} \mathrm{C}$ and Parson's law drop size distribution for $0{ }^{\circ} C[13]$.

Again, the radio path lengths $L_{A}$ and $L_{B}$ can be described by Equation (11):

$$
\begin{aligned}
& L_{A}=\left(H_{A}-H_{S}\right) / \sin \vartheta \\
& L_{B}=\left(H_{B}-H_{S}\right) / \sin \vartheta
\end{aligned}
$$

Matricciani [4] revealed that the probability distribution function that was generated by SST can consistently be represented by

$$
A=\left[C_{0} K_{A} R^{\alpha_{A}}+\left(1-C_{0}\right) K_{B}(3.134 R)^{\alpha_{B}}\right] L^{m}(d B)
$$

Where $L(\mathrm{~km})$ is typifies the long term slant path in the rainfall (and $m$ is a random variable) as given by [9] and described by [14] to give

$$
L=L_{A}+L_{B}
$$

The value of the random variable $m$ is derived from

$$
m=\Delta A / A / \Delta L / L
$$

The integration constant, $C_{0}$ is given as

$$
C_{0}=L_{A} / L=\frac{0.4}{H_{B}-H_{S}}
$$

$H_{B}$ is the vertical dimension of the melting layer's tip and $0.4 \mathrm{~km}$ is supposed thickness of the melting layer.

\subsubsection{The ITU-R. P. 618-12 Model}

The ITU-R Recommendation P.618-12 rain attenuation prediction model [15] is the only rain attenuation prediction model for consideration of degrading effects of rain on satellite communication equipment. $R_{0.01}$ (rain rate at $0.01 \%$ of the time exceeded) is the major input to this model and the subsequent attenuation at $0.01 \%\left(A_{0.01}\right)$ was employed as the foundation in approximating the attenuation exceeded at other percentages of time excedances $\left(A_{\% p}\right)$. However, the shortcomings of this model are the assumption of constant rain height and a static reduction factor in the computation of the slant path attenuation exceeded. These assumptions have been observed by researchers in tropical and equatorial locations to be inappropriate because effective rain height $\left(H_{R}\right.$ ) is acknowledged to positively dependent on rainfall intensity [11], [1620]. The procedure for computing the cumulative rain attenuation distribution functions along earth-space satellite link can be obtained in open literatures as well as at the ITU website. The "effective path length" $L_{\text {eff }}(\mathrm{km})$ through rain is derived by the product of the horizontally adjusted slant path and the vertical reduction factor. This is given as:

$$
L_{e f f}=L_{h 0.01} r_{v 0.01}(k m)
$$

For a typical year, the predicted satellite attenuation exceeded for $0.01 \%\left(A_{0.01}\right)$ is

$$
A_{0.01}=\gamma_{0.01} L_{e f f}(d B / k m)
$$

Therefore, predicted attenuation exceeded for other percentages $\% p$ in a typical year are derived from Equation (17) adopting the extrapolation given in Equation (18):

IJEEI, Vol. 6, No. 1, March 2018 : $61-69$ 


$$
A_{\% p}=A_{0.01}\left(\frac{p}{0.01}\right)^{-\left[0.655+0.033 \ln p-0.045 \ln A_{0.01}-z \sin \theta(1-p)\right]}(d B)
$$

Where $p$ is the percentage probability of interest and $z$ is given by

$$
\begin{aligned}
& \text { For } p \geq 1.0 \%, z=0 \\
& \text { For } p<1.0 \%, z=\left\{\begin{array}{l}
0 ; \text { for } / \phi / \geq 36^{\circ} \\
z=-0.005(/ \phi /-36) \text { for } \theta \geq 25^{\circ} \text { and } / \phi /<36^{\circ} \\
z=-0.005(/ \phi-36 /)+1.8-4.25 \sin \theta, \text { for } \theta<25^{\circ} \text { and } / \phi /<36^{\circ}
\end{array}\right.
\end{aligned}
$$

\subsubsection{Bryant Proposed Model}

This model [21] utilized the theory of "effective rain cell" and variable rain height to determine rain attenuation the distribution of at any location of by engaging the following parameters: $R, H_{S}$, and elevation angle of earth the station $(\theta)$. All these are used as inputs in computing the attenuation exceeded. The probability factor $(\mathrm{PF})$ parameter is derived from

$$
P R=1+\frac{2}{\pi} \frac{L}{D}
$$

Where $\mathrm{D}$ is the rain cell diameter, and is defined as

$$
D=340 R_{p}^{-1.2}
$$

Also, the horizontal projection $(L)$ is given as

$$
L=\frac{h_{r}}{\tan \theta}
$$

Afterward, the rainfall height $\left(h_{r}\right)$ is obtained from the expression,

$$
h_{r}=4.5+0.0005 R_{p}^{1.65}(k m)
$$

Lastly, the slant path attenuation exceeded $\left(A_{s}\right)$ is calculated using the expression:

$$
A_{s}=1.57 D_{m} k_{n} \gamma_{p} \frac{L_{s}}{\xi L+D}(\mathrm{~km})
$$

Where the slant path length $\left(L_{s}\right)$ and the specific attenuation $\left(\gamma_{p}\right)$ are previously given in Equations (5) and (2) respectively while $k_{n}$ is the number of rain cells involved. That is,

$$
\begin{aligned}
& D_{m}=\left(\frac{2}{\pi}\right) D(k m) \\
& k_{n}=\exp \left(0.007 R_{p}\right)(k m) \\
& \xi=\left\{\begin{array}{l}
\frac{1}{\sqrt{2}} \exp (\sin \theta) \\
1.1 \tan \theta
\end{array}\right\}_{\theta>55^{\circ}}^{\theta \leq 55^{\circ}}
\end{aligned}
$$




\subsubsection{Dissanayake, Allnutt and Haidara (DAH)}

This rain attenuation prediction model was formulated by Asoka Dissanayake, Jeremy Allnutt and Fatim Haidara [22]. There are similarities between it and the ITU-R. P. 618-12 [15] rain model. Here, rain intensity at the $0.01 \%$ of the time is the input to this model. Furthermore, inhomogeneities of rain in both the vertical and horizontal directions are accommodated. This approach is valid across a range of frequency of between 4-35 GHz and a percentage probability range of between $0.001 \%-10 \%$ of time exceeded.

$$
A_{p=} A_{0.01}\left[\frac{p}{0.01}\right]^{-\left(0.655+0.033 \ln (p)-0.045 \ln \left(A_{0.01}\right)-z(1-p) \sin \theta\right)} \mathrm{dB}
$$

\section{RESEARCH METHOD}

Satellite attenuation data for the $\mathrm{Ku}$ band $(12.675 \mathrm{GHz})$ at $0.01 \%$ of the time were sourced from NigComSat-2, a Nigerian satellite communication satellite owned by NASRDA (National space research and development agency) and launched into space into space on August 17, 2011. The slant path attenuation exceedances for other percentages of the time for the average year were obtained using statistical interpolation and extrapolation methods. The slant path measured attenuation data for the Ka frequency band $(19.45 \mathrm{GHz})$ at $0.1 \%, 0.01 \%$ of the time exceeded were retrieved from the contour maps in the work published by Ojo et al. [23]. Similarly, attenuation exceedances for other corresponding percentages of time for an average year were attained by statistical interpolation and extrapolation methods. These data were thereafter scaled up to $26 \mathrm{GHz}$ by adopting the procedures provided in ITU-R. P.618-12 [15].

Monthly rainfall data, recorded hourly were sourced from NIMET (Nigerian Meteorological Services) for Lagos, Nigeria spanning a period of three years (January 2010 through December 2012). Lagos $\left(6.35^{\circ} \mathrm{N}, 3.23^{\circ} \mathrm{E}\right)$ is a station lying within a coastal rain forest region of tropical Nigeria and with an altitude of $38 \mathrm{~m}$ above the $\mathrm{msl}$ (mean sea level). The annual rainfall is $1425 \mathrm{~mm}$. The measurement setup comprises a rain gauge (the buck-type) to record the point rainfall rate.

The rain rate at $0.01 \%\left(\mathrm{R}_{0.01}\right)$ of time was calculated from the total annual accumulation using the Chebil model [24] in Equation (4). Thereafter, the hourly recorded rain rate was then converted to 1-min rain rate at $0.01 \%$ of time exceedance, $R_{0.01}$ was obtained also from [19] as expressed in Equations (28) and (29).

$$
R_{0.01}=\alpha M^{\beta}
$$

Where $\alpha$ and $\beta$ are regression coefficients. The regression coefficient $\alpha$ and $\beta$ are defined as [19]

$$
\alpha=12.2903 \text { and } \beta=0.2973
$$

$$
P_{60}(P)=R_{1}(P) / R_{60}(P)
$$

With $P_{60}(P)$ expressed as combined Power-Exponential Law

$$
\rho_{60}=0.772 p^{-0.041}+1.141 * \exp (-2.570 * p)
$$

Where the probability of occurrence is $P, R_{1}(P)$ is the 1-min rainfall rate and $R_{60}(P)$ is the 60-min rain rate.

\section{RESULTS AND ANALYSIS}

For $12 \mathrm{GHz}$ (Figures 1 (a) and 2 (a)) at $0.001 \%$ of the time, SST and DAH models were the closest to the measured value, while Bryant model showed the worst deviation. Also, at $P=0.01 \%$, ITU-R, DAH and Bryant models closely matched the measurement, while SST and SAM prediction models largely overestimated the measured value. Overall, ITU-R presented the best performance, closely followed by the DAH model, except at $0.1 \% \leq p \leq 1.0 \%$ (notwithstanding that both models underestimated the measurement for percentages of time). 


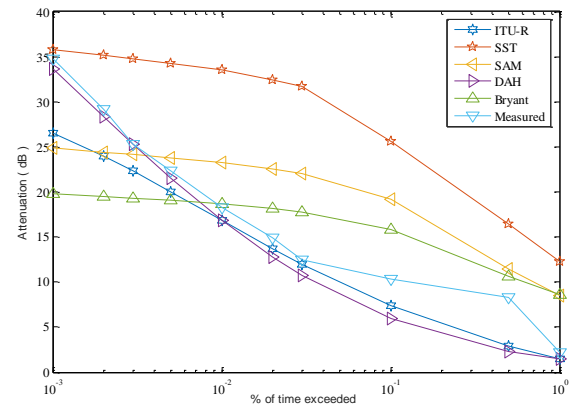

(a)

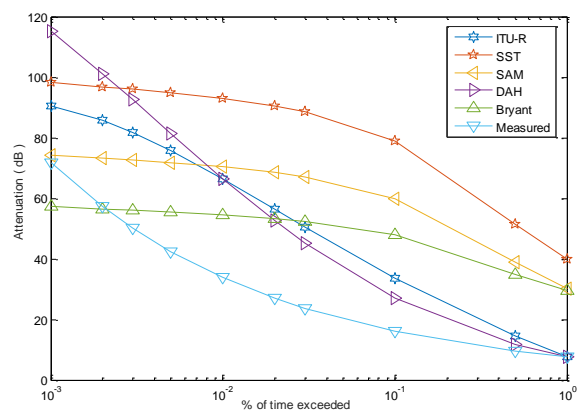

(b)

Figure 1. Cumulative distributions of attenuation for Lagos at (a) $12 \mathrm{GHz}$ and (b) $20 \mathrm{GHz}$

However, at $26 \mathrm{GHz}$, as shown in Figures 1 (b) and 2 (b), all the prediction models investigated performed poorly by overestimating the measurement except for Bryant which underestimated the measured value at $p=0.001 \%$ of the time; with ITU-R and DAH which matched the measurement at $p=1.0 \%$. More so at $p=0.001 \%$, only SAM model closely matched the measured attenuation value, while at $p=0.002 \%$, Bryant model exhibited the best performance.

Furthermore, Figures 3 (a) and (b) depicts the performances vis-à-vis the correlation between predicted and measured attenuation for all prediction models of interest, while the relationship between frequency variations with slant path attenuation is presented in Figure 4.

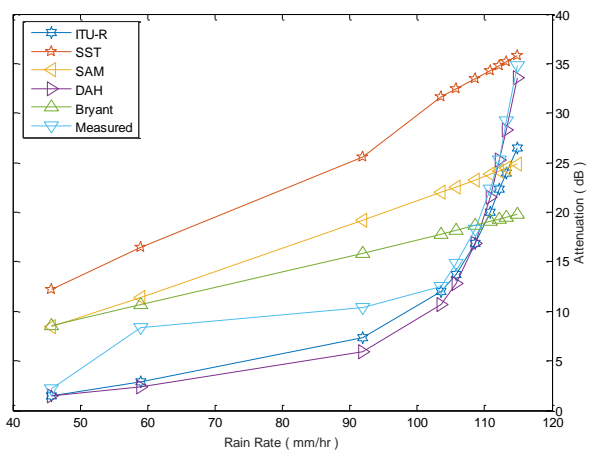

(a)

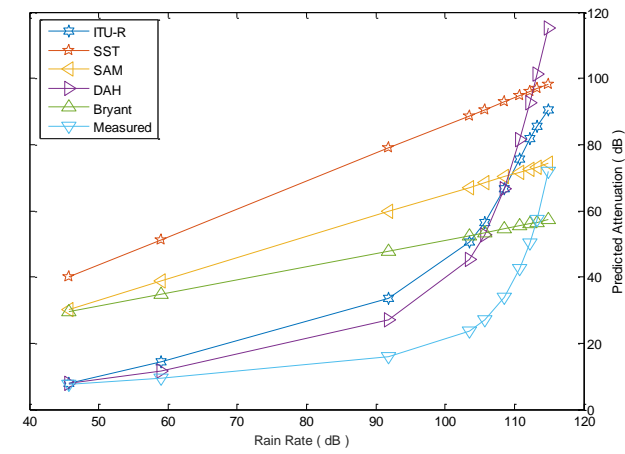

(b)

Figure 2. Equal probability plots of rain rate and slant path attenuation for Lagos at (a) $12 \mathrm{GHz}$ and (b) 26 $\mathrm{GHz}$

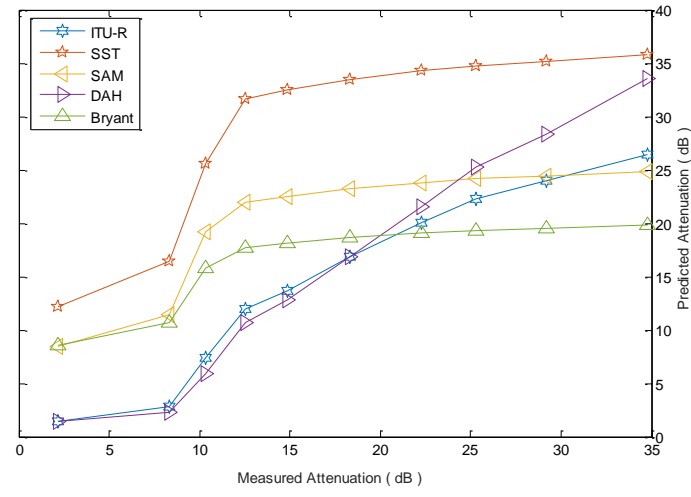

(a)

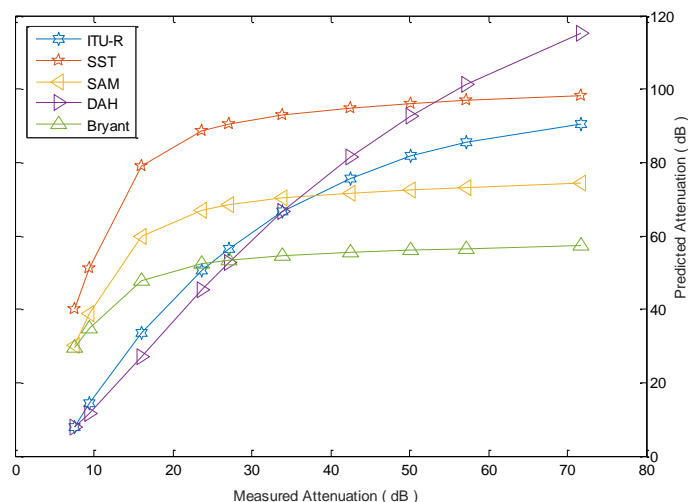

(b)

Figure 3. Comparison of predicted against measured attenuation at (a) $12 \mathrm{GHz}$ and (b) $26 \mathrm{GHz}$ 


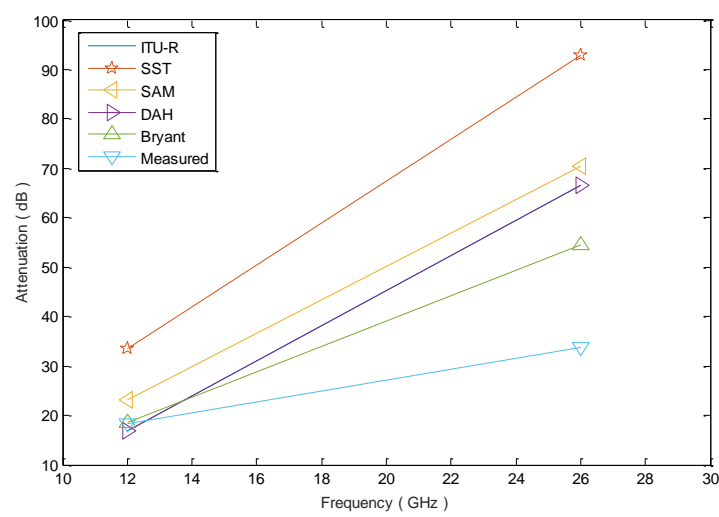

Figure 4. Relationship between slant path attenuation with frequency

Table 1 presents comparison of mean error, standard deviation and RMS (root mean square) for different prediction models at both $\mathrm{Ku}$ and $\mathrm{Ka}$ frequency bands. Again, from the RMS statistical values, ITU$\mathrm{R}$ and DAH predictions models exhibited the most impressive performances, both at $\mathrm{Ku}$ and $\mathrm{Ka}$ bands; and giving the evaluation technique approved by the ITU-R P.311-15 [25], the prediction model with smallest values of the statistical parameters are adjudged the best prediction method. Hence, from the Table, the ITU$\mathrm{R}$ model presented the overall best performance at the $\mathrm{Ku}$ band while the DAH proposed prediction model showed the best performance at the Ka frequency band (just slightly better than the ITUR model).

Table1. Comparison of mean error, standard deviation and RMS for different prediction models at $12 \mathrm{GHz}$ and $26 \mathrm{GHz}$

\begin{tabular}{|c|c|c|c|c|c|c|c|c|c|c|c|}
\hline \multirow[t]{2}{*}{ Parameter } & \multicolumn{3}{|c|}{$\begin{array}{l}\text { Prediction } \\
\text { model }\end{array}$} & \multicolumn{3}{|c|}{ Time percentage (\%p) } & \multirow[b]{2}{*}{0.02} & \multirow[b]{2}{*}{0.03} & \multirow[b]{2}{*}{0.1} & \multirow[b]{2}{*}{0.5} & \multirow[b]{2}{*}{1.0} \\
\hline & & 0.001 & 0.002 & 0.003 & 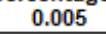 & 0.01 & & & & & \\
\hline \multirow{5}{*}{ Mean } & & & & & $12 \mathrm{GHz}$ & & & & & & \\
\hline & $\begin{array}{l}\text { ITU-R } \\
\text { SST }\end{array}$ & $\begin{array}{r}-0.0240 \\
0.0027\end{array}$ & $\begin{array}{r}-0.0179 \\
0.0204\end{array}$ & $\begin{array}{r}-0.0119 \\
0.0375\end{array}$ & $\begin{array}{c}-0.0102 \\
0.0537\end{array}$ & $\begin{array}{r}-0.0080 \\
0.0829\end{array}$ & $\begin{array}{r}-0.0078 \\
0.1183\end{array}$ & $\begin{array}{r}-0.0044 \\
0.1531\end{array}$ & $\begin{array}{r}-0.0286 \\
0.1475\end{array}$ & $\begin{array}{r}-0.0657 \\
0.0974\end{array}$ & $\begin{array}{r}-0.0319 \\
0.4620\end{array}$ \\
\hline & SAM & -0.0286 & -0.0163 & -0.0045 & 0.0068 & 0.0271 & 0.0517 & 0.0759 & 0.0854 & 0.0371 & 0.2905 \\
\hline & $\mathrm{DAH}$ & -0.0034 & -0.0029 & -0.0002 & -0.0035 & -0.0080 & -0.0140 & -0.0144 & -0.0424 & -0.0720 & -0.0319 \\
\hline & Bryant & -0.0431 & -0.0332 & -0.0237 & -0.0145 & 0.0020 & 0.0222 & 0.0420 & 0.0533 & 0.0277 & 0.2932 \\
\hline \multirow[t]{5}{*}{ Std. Dev. } & ITU-R & 0.2376 & 0.2371 & 0.2728 & 0.2727 & 0.2726 & 0.2726 & 0.2726 & 0.2740 & 0.2803 & 0.2744 \\
\hline & SST & 1.7139 & 1.7138 & 1.7135 & 1.7131 & 1.7119 & 1.7099 & 1.7071 & 1.7076 & 1.7112 & 1.6505 \\
\hline & SAM & 1.0053 & 1.0056 & 1.0057 & 1.0057 & 1.0053 & 1.0044 & 1.0028 & 1.0021 & 1.0050 & 0.9628 \\
\hline & $\mathrm{DAH}$ & 0.2915 & 0.2915 & 0.2915 & 0.2915 & 0.2916 & 0.2918 & 0.2918 & 0.2946 & 0.3002 & 0.2932 \\
\hline & Bryant & 0.8727 & 0.8731 & 0.8735 & 0.8737 & 0.8738 & 0.8735 & 0.8728 & 0.8721 & 0.8733 & 0.8231 \\
\hline \multirow[t]{5}{*}{ RMS } & ITU-R & 0.2746 & 0.2737 & 0.2730 & 0.2729 & 0.2728 & 0.2727 & 0.2726 & 0.2755 & 0.2879 & 0.2762 \\
\hline & SST & $\begin{array}{l}1.7139 \\
\end{array}$ & 1.7137 & 1.7131 & 1.7123 & 1.7099 & 1.7058 & 1.7002 & 1.7012 & 1.7084 & 1.5845 \\
\hline & SAM & 1.0049 & 1.0054 & 1.0057 & 1.0056 & 1.0050 & 1.00 & 0.99 & 0.98 & 1.00 & 0.9180 \\
\hline & $\mathrm{DAH}$ & 0.2915 & 0.2915 & 0.2915 & 0.2915 & 0.2917 & 0.2922 & 0.2922 & 0.2976 & 0.3088 & 0.2950 \\
\hline & Bryant & 0.8716 & 0.8725 & 0.8731 & 0.8735 & 0.8738 & 0.8732 & 0.8717 & 0.8705 & 0.8729 & 0.7691 \\
\hline \multirow{6}{*}{ Mean } & & & & & $26 \mathrm{GHz}$ & & & & & & \\
\hline & ITU-R & 0.0262 & 0.0496 & 0.0628 & & 0.0963 & & 0.1135 & 0.1100 & 0.0520 & 0.0029 \\
\hline & SST & & & & 0.1233 & & & & & & \\
\hline & SAM & 0.0035 & 0.0279 & 0.0447 & 0.0689 & 0.1076 & 0.1530 & 0.1834 & 0.2737 & 0.3099 & 0.3005 \\
\hline & & 0.0603 & 0.0768 & 0.0845 & 0.0916 & & & 0.09 & & & 0.0029 \\
\hline & Bryan & -0.0202 & -0.0013 & 0.0118 & 0.0307 & 0.0611 & 0.0972 & 0.1216 & 0.1990 & 0.2692 & 0.2902 \\
\hline \multirow[t]{5}{*}{ Std. Dev. } & ITU-R & 0.7870 & 0.7859 & 0.7849 & 0.7835 & 0.7815 & 0.7799 & 0.7792 & 0.7797 & 0.7857 & 0.7874 \\
\hline & & 2.6941 & 2.6935 & 2.6928 & & & & & & & \\
\hline & SAM & 1.8368 & 1.8366 & 1.8363 & 1.8355 & 1.8337 & 1.8304 & 1.8277 & 1.8163 & 1.8105 & 1.8121 \\
\hline & DAH & 0.7522 & 0.7507 & 0.7498 & 0.7490 & 0.7484 & 0.7487 & 0.7491 & 0.7514 & 0.7542 & 0.7546 \\
\hline & Bryant & 1.4996 & 1.4997 & 1.1996 & 1.4994 & 1.4984 & 1.4965 & 1.4947 & 1.4864 & 1.4753 & 1.4714 \\
\hline \multirow[t]{5}{*}{ RMS } & ITU-R & 0.7865 & 0.7843 & 0.7824 & 0.7796 & 0.7756 & 0.7723 & 0.7709 & 0.7719 & 0.7840 & 0.7874 \\
\hline & SST & 2.6939 & 2.6926 & 2.6913 & 2.6887 & 2.6830 & 2.6739 & 2.6662 & 2.6361 & 2.6208 & 2.6250 \\
\hline & & 1.8368 & 1.8364 & 1.8357 & 1.8342 & 1.8305 & 1.8240 & 1.8184 & 1.7956 & 1.7838 & 1.7870 \\
\hline & DAH & 0.7497 & 0.7467 & 0.7451 & 0.7434 & 0.7422 & 0.7427 & 0.7435 & 0.7482 & 0.7538 & 0.7546 \\
\hline & Bryant & 1.4994 & 1.4997 & 1.4996 & 1.4991 & 1.4972 & 1.4934 & 1.4898 & 1.4731 & 1.4506 & 1.4425 \\
\hline
\end{tabular}

\section{CONCLUSION}

Performances of the various prediction models of interest were investigated at both $\mathrm{Ku}$ and $\mathrm{Ka}$ frequency bands to ascertain the suitability or otherwise of these models as choice rain attenuation models for a tropical station like Lagos, Nigeria. Again, the ITU-R prediction model has shown reliability at ku band but the performances seem to diminish at a higher frequency band $(26 \mathrm{GHz})$. However, at $26 \mathrm{GHz}, \mathrm{DAH}$ proposed rain attenuation model showed a slight improvement over the ITU-R model even though both models have remarkable similarities in their formulations. Moreover, the show of good performances by the 
ITU-R model may be attributable to its assumption of homogeneity of rainfall along the slant path, which may not entirely correct for stations with low elevation angles, such as those in the tropical regions because the slant path are much more lengthened; and may consequently stretch beyond one rain cell. In summary, there is need to update (or possibly replace) the ITU-R model with a more suitable one for the tropical regions to improve the accuracy and reliability of slant path rain attenuation predictions results turned out by the model for use by satellite communication equipment designers and engineers for both domestic and commercial ( $p=0.01 \%)$, as well as military ( $p=0.001 \%)$ applications.

\section{REFERENCES}

[1] Himadri Chakrabarty et al. Relationship of attenuations at ka and ku bands with sea surface temperature of Pacific Ocean. International Journal of Scientific and Engineering Research, 2014; 5(2): 194-197.

[2] Sharul Kama.A.R et al. Rain attenuation study over terrestrial and earth-satellite links in Malaysia.2014; 1-4.

[3] Dalia Das et al. Time series predictor of Ku band rain attenuation over an Earth-Space path at a tropical location. Int. J. Satell. Commun. Network. 2012; 30:19-28.

[4] Abdulrahman A. Y. et al. Comparison of measured rain attenuation in the 10.982-Ghz band with predictions and sensitivity analysis. Int. J. Satell. Commun. Network, 2011; 3(4): 477-483.

[5] Li Rong. A new method of uplink power compensation of rain attenuation of satellite communication system. International Conference on Automation, Mechanical Control and Computational Engineering. 2015: 2181-2185.

[6] Moupfouma F. (1987). More about Rainfall Rates and Their Prediction for Radio System Engineering. Institution of Engineering \& Technology, IEE Proceedings. 1987; 34, Pt. H(6): 527-537

[7] Stutzman W, Yon K. A simple rain attenuation model for earth-space radio links operating at 10-35 GHz. Radio science. 1986; 21(1): 65-72

[8] Mandeep J. S, Tanaka K. Effects of atmospheric parameters on satellite link. Int. J. Infrared Millimeter Waves. 2007; 28: 789-795.

[9] ITU-R. P.839-4, Rain height model for prediction methods, in Recommendation ITU-R P Series; 2013.

[10] Drufuca G. Rain Attenuation Studies. United States Air Force: Canada: 1-105. 1973.

[11] Yussuff A. I. O. Analysis of Selected Earth-Space Rain Attenuation Models for a Tropical Station, Indonesian Journal of Electrical Engineering and Computer Science. 2016; 3(2): 383-391.

[12] ITU-R. P.838-3, Specific attenuation model for rain for use in prediction methods, in Recommendation ITU-R P Series; 2005.

[13] Magorri D. Computed transmission through rain in the $1-400 \mathrm{GH} \mathrm{z}$ frequency range for spherical and elliptical drops and any polarization. Alta Frequena. 1981; 50: 262-273.

[14] Matricciani E. A fundamental differential equation that links rain attenuation to the rain rate measured at one point, and its applications in slant paths. In EuCAP 2006. Nice, France. 2006.

[15] ITU-R. P. 618-12, Propagation Data and Prediction Methods Required for the Design of Earth-Space Telecommunications Systems, in Recommendation ITU-R P Series; 2015.

[16] Yussuff A. I. O. Characterization of bright-band in a tropical station for satellite communication. Ph.D Thesis. Universiti Teknologi Malaysia: Malaysia; 2014.

[17] Yussuff A. I. O, Hamzat N, Khamis N. H. H. (2017), Site Diversity Application on Rain Attenuation for Lagos. Indonesian Journal of Electrical Engineering and Informatics, 2017, 5(1): 77-84.

[18] Abdulrahman A. Y. et al. Statistical evaluation of measured rain attenuation in tropical climate and comparison with prediction models. Journal of Microwaves, Optoelectronics and Electromagnetic Applications, 2016; 15(2): 123134.

[19] Parth P, Rutvij J. Performance Analysis and Simulation of Rain Attenuation Models at 12-40 GHz Band for an Earth Space Path over Indian Cities. 7th International Conference on Communication, Computing and Virtualization. Procedia Computer Science, 2016. 79: 801- 808

[20] Sujan S, Dong-You C. Rain attenuation statistics over millimeter wave bands in South Korea, Journal of Atmospheric and Solar-Terrestrial Physics, 2017.152: 1-10.

[21] Bryant G. et al. Rain attenuation statistics from rain cell diameters and heights. International journal of satellite communications, 2001; 19(3): 263-283.

[22] Dissanayake A, Allnutt J, Haidara F. A prediction model that combines rain attenuation and other propagation impairments along earth-satellite paths. Antennas and Propagation, IEEE Transactions on. 1997; 45(10): 15461558.

[23] Ojo J. S, Ajewole M. O, Sarkar S. K. Rain rate and rain attenuation prediction for satellite communication in ku and ka bands over Nigeria. Progress in Electromagnetics Research B. 2008; 5: 207-223.

[24] Chebil J, Rahman T.A. Rain rate statistical conversion for the prediction of rain attenuation in Malaysia. Electronic Letters. 1999; 35: 1019-1021.

[25] ITU-R P.311-15, Acquisition, presentation and analysis of data in studies of tropospheric propagation, in Recommendation ITU-R P Series; 2015. 